\title{
Observation of Crack Evolution in Nickel steel of different Thermal Treatment
}

\author{
Shuo Li \\ National engineering and research \\ center of advanced rolling, University \\ of Science and Technology Beijing, \\ Xueyuan Road, Haidian District, \\ Beijing, 10083, China \\ lishuo2010d@163.com
}

\author{
Yide Wang \\ Taiyuan Iron \& Steel (Group) Co., Ltd, \\ Taiyuan, 030003, China
}

\author{
Di Tang \\ National engineering and research \\ center of advanced rolling, University \\ of Science and Technology Beijing, \\ Xueyuan Road, Haidian District, \\ Beijing, 10083, China
}

\begin{abstract}
Formation and propagation of crack in quenching+tempering(QT) and quenching+ intercritical quenching+ tempering (QLT) treated $\mathrm{Fe}-9 \% \mathrm{Ni}-\mathrm{C}$ alloys were investigated by means of in-situ scanning electron microscope (SEM) and transmission electron microscopy (TEM).The sample treated by QLT showed better cryogenic toughness than QT treatment. High content of retained and reversed austenite in QLT-treated alloy could be tested which located not only on the high angle grain boundaries such as prior austenite boundary and packet boundary but also within the laths which was stable during loading because of protection of harder phase. Retained and reversed austenite in QT treated alloy mainly located at high angle grain boundaries and was weak in stability during loading, could not improve cryogenic toughness of the alloy comparatively.
\end{abstract}

Keywords-QLT treatment; QT treatment; In-situ tensile test; Retained and reversed austenite

\section{INTRODUCTION}

In recent years, clean and efficient resource such as natural gas rather than coal and oil--the conventional means is of particular concern, because of sustainable development and harmony between human society and environment. The natural gas is usually liquefied at $-196^{\circ} \mathrm{C}$ and stored in tanker which is made of austenite stainless steel or $\mathrm{Fe}-9 \% \mathrm{Ni}$ alloy. The Fe-9\%Ni steel has been investigated intensively for its relatively lower productive cost. Intercritical quenching which is carried out by heating to the dual-phase $(\alpha+\gamma)$ region and followed by a rapid cooling, has been utilized in many alloys due to its many and varied advantages ${ }^{[1,2]}$. This critical quenching is specially used to produce advanced $9 \% \mathrm{Ni}$ cryogenic steel for fabrication of large LNG(liquefied natural gas) container serving at or below $-162^{\circ} \mathrm{C}$. This complex heat treatment consisting of sequential process of quenching, intercritical quenching and tempering is sometimes reported as quenching, lamellarizing and tempering (QLT) process. Generally, a mixed structure of lath martensite matrix and hypoeutectoid ferrite formed during the intercritical quenching ${ }^{[3]}$, and a quantity of retained and reversed austenite which could keep thermodynamically stable down to $-196^{\circ} \mathrm{C}$ formed in subsequent tempering process. The retained and reversed austenite can improve comprehensive mechanical properties via playing as an impact cushion, absorbing some harmful elements which have a higher solubility in $\gamma$-phase than in $\alpha$-phase, and undergoing deformation-induced martensitic transformation of retained and reversed austenite (TRIP assisted effect) ${ }^{[4-6]}$. The retained and reversed austenite becomes mechanically unstable and transformed into new martensite with crystallography orientation different to the matrix martensite lath when a impact testing was carried out at $-196^{\circ} \mathrm{C}$. Cryogenic toughness is preferable to consideration for safety concern. The conventional thermal process QT treatment (quench+temper) and advancing QLT treatment are utilized in this paper in order to clarify the different fracture behavior after heat treatments and to find out their main fracture mechanism.

\section{EXPERIMENTAL PROCEDURES}

The steel used in this paper was melted in vacuum induction furnace in Central Iron and Steel Research Institute of China. Table 1 listed its chemical compositions. The ingot was forged into $80 \mathrm{~mm} \times 80 \mathrm{~mm} \times 100 \mathrm{~mm}$ slab, and then homogenized at $1150^{\circ} \mathrm{C}$ for $1 \mathrm{~h}$, hot-rolled to $15 \mathrm{~mm}$ thickness plate in the range of $1150^{\circ} \mathrm{C}-800^{\circ} \mathrm{C}$. One plate was quenched at $800{ }^{\circ} \mathrm{C}$ and isothermal tempered at $540{ }^{\circ} \mathrm{C}$ for $1 \mathrm{~h}$ finally cooled in water, the other was quenched at $800^{\circ} \mathrm{C}$ firstly, reheated to $650^{\circ} \mathrm{C}$ for $1 \mathrm{~h}$ and quenched in water, finally isothermal tempered at $540^{\circ} \mathrm{C}$ for $1 \mathrm{~h}$ and cooled in water.

TABLE1. CHEMICAL COMPOSITIONS OF 9\%NI STEEL (WT\%)

\begin{tabular}{cccccc}
\hline $\mathrm{C}$ & $\mathrm{S}$ & $\mathrm{Ni}$ & $\mathrm{P}$ & $\mathrm{N}$ & $\mathrm{Mn}$ \\
\hline $\mathbf{0 . 1}$ & $\mathbf{0 . 0 1}$ & $\mathbf{9 . 1}$ & $\mathbf{0 . 0 0 4 7}$ & $\mathbf{0 . 0 0 3 1}$ & $\mathbf{0 . 4}$ \\
\hline
\end{tabular}

The cylinder samples with diameter of $8 \mathrm{~mm}$ were machined from the plates for tensile testing, and three standard impact samples with size of $10 \mathrm{~mm} \times 10 \mathrm{~mm} \times 55 \mathrm{~mm}$ were machined for Charpy-V notch $(\mathrm{CVN})$ impact testing at $-196^{\circ} \mathrm{C}$. The content of retained and reversed austenite was estimated by X-ray diffraction (XRD) comparing the 
integrated peak intensities of the $(002) \alpha$ and $(220) \gamma$ phase $\mathrm{p}^{[7,8]}$. The samples were polished and etched in $7 \%$ nital solution, and the fracture propagation during tensile testing was observed by JSM-5800 in-situ scanning electron microscope (SEM) and JEM-2000 transmission electron microscope (TEM).

\section{RESULTS AND DISCUSSION}

The mechanical properties of QT and QLT treated specimen together with the volume fraction of retained and reversed austenite were shown in table 2. Table 2 shows that the yield strength of the specimen treated by QT is a little higher than that of QLT, the tensile strength of the specimen treated by QT was lower than that of QLT treated specimen, and the elongation of the specimen treated by QT was much lower than that of QLT treated specimen. The reason of that is closely related to the microstructure. The microstructures of two specimen are comprised of martensite matrix and different volumes of austensite. The martensite could enhance the yield strength, and the austensite could improve the plasticity. However, cryogenic toughness of the specimen treated by QLT was much higher than that of QT treated specimen, which is because the volume fraction of retained and reversed austenite was about 3 times of that of QT treated specimen. It was reported that cryogenic toughness was significantly improved by retained and reversed austenite ${ }^{[9,10]}$.

TABLE 2. VOLUME FRACTION OF RETAINED AND REVERSED AUSTENSITE AND MECHANICAL PROPERTIES OF 9\%NI STEEL WITH QT AND QLT

\begin{tabular}{cccccc}
\hline $\begin{array}{c}\text { Heat } \\
\text { treatm } \\
\text { ent }\end{array}$ & $\begin{array}{c}\text { Volu } \\
\text { me } \\
\text { fract } \\
\text { ion }\end{array}$ & $\begin{array}{c}\text { YS/ } \\
\text { MPa }\end{array}$ & $\begin{array}{c}\text { TS/ } \\
\text { MPa }\end{array}$ & $\begin{array}{c}\text { Elongati } \\
\text { on/\% }\end{array}$ & $\begin{array}{c}\text { Akv(-1 } \\
\left.96^{\circ} \mathrm{C}\right) \\
/ J\end{array}$ \\
\hline QT & $\mathbf{2 . 6 \%}$ & 735 & 755 & 20 & 130 \\
\hline QLT & $11 \%$ & 708 & 778 & 24 & 186 \\
\hline
\end{tabular}

\section{IN-SITU SEM OF FRACTURE IN QT-TREATED SAMPLE}

Microstructure consisting of lath martensite with size about $10-20 \mu \mathrm{m}$ in the sample subjected to QT treatment before tension was shown in Fig.1. It was showed that retained and reversed austenite in QT treated sample mainly located at high angle grain boundaries.

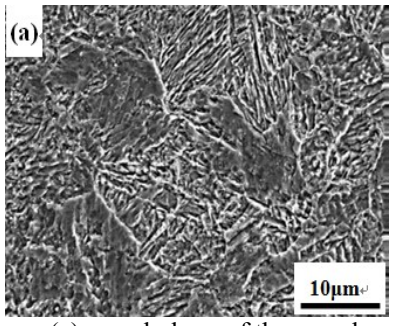

(a) morphology of the sample;

Fig.1. Microstructure of QT-treated sample before tension deformation increased, stress concentration increased and finally led to the formation of the fracture, whose direction was parallel to the maximal shear stress, $45^{\circ}$ to tensile direction. Distinct deformation band emerged at the tip, the original irregular laths gradually rotated to the direction which was parallel to tensile direction. This was in accordance to the report $^{[11]}$. Retained and reversed austenite along the grain boundary coordinated with the matrix which led to greater deformation giving rise to transformation. In contrast, retained and reversed austenite between laths was protected by adjacent laths, deformed slightly and it could alleviate the deformation. That was why retained and reversed austenite between laths showed better stability.
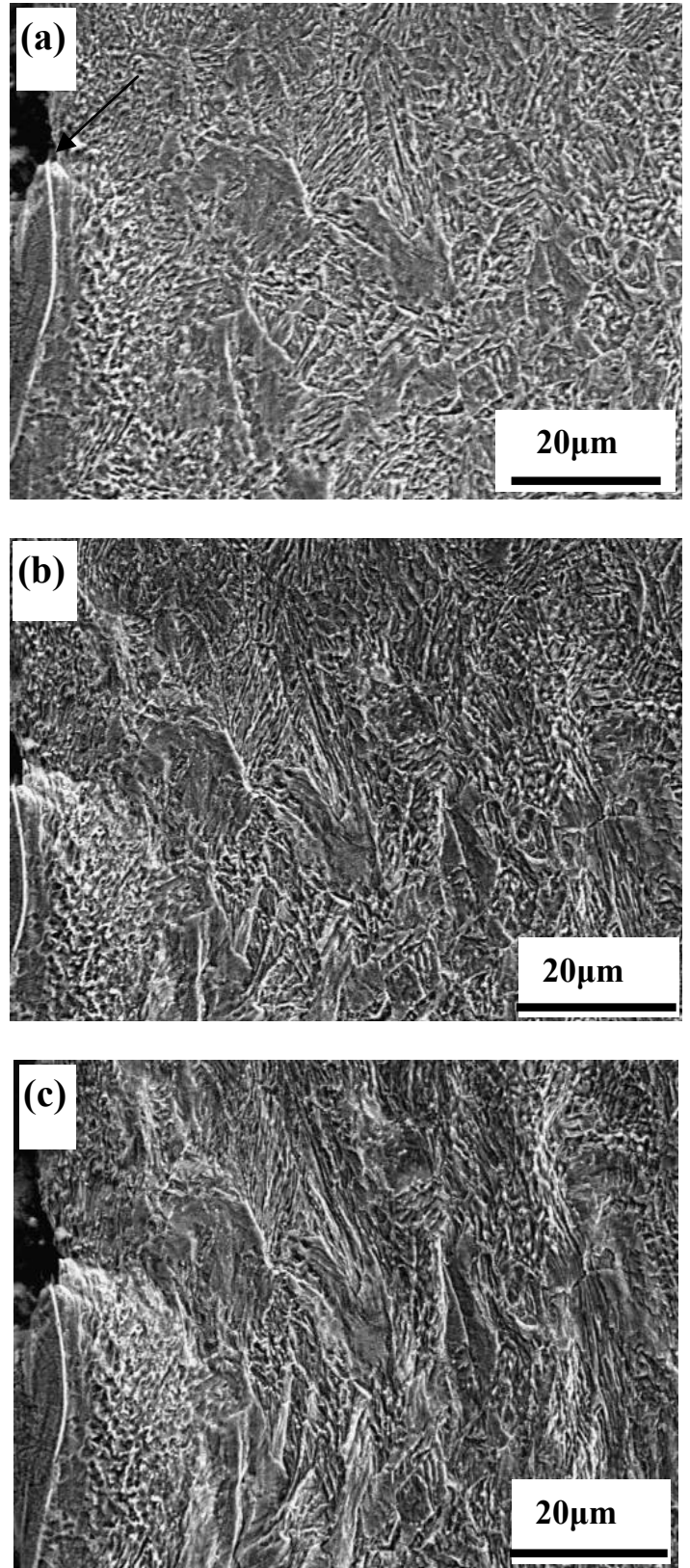

At the very beginning of the tension, stress concentration formed near the notch, indicated as arrow in Fig.2a. With 


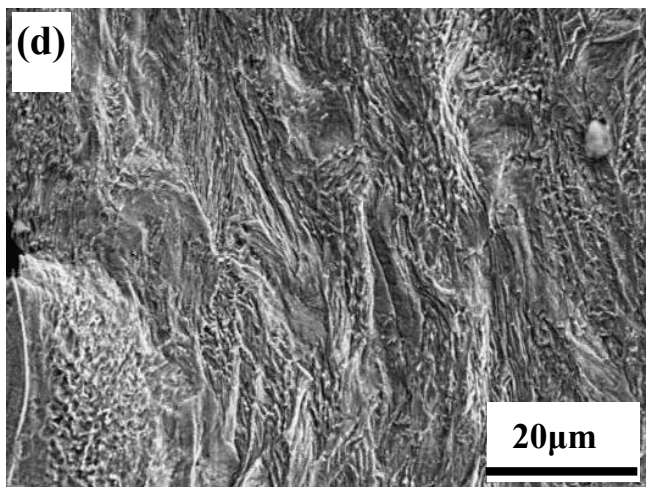

Fig.2. Microstructural evolution of QT-treated sample during tension.

The propagation of the fracture was shown in Fig.3. During loading, the crack propagated along a curve course. When the loading force increased from $100 \mathrm{~N}$ to $250 \mathrm{~N}$, the crack extended under radial force especially forming micro-pore in the weak zone at the tip of the crack. The formation and propagation of the micro-crack released the stress, was beneficial to slide and to form zigzag shape propagation path ${ }^{[12,13]}$ in shear deformation. It contained shear crack and congestion of micro-pore mechanism, which was ductile fracture, as shown in Fig.3a-c. Meanwhile, the crack extended along the direction of plastic strain concentration, $30^{\circ}$ to the tensile direction. Morphology of the fracture tip was indicated in Fig.3d-f. The laths in certain area turned to the tensile direction, which was perpendicular to the propagation of the crack. It was difficult to rotate further, almost extended across the lath.
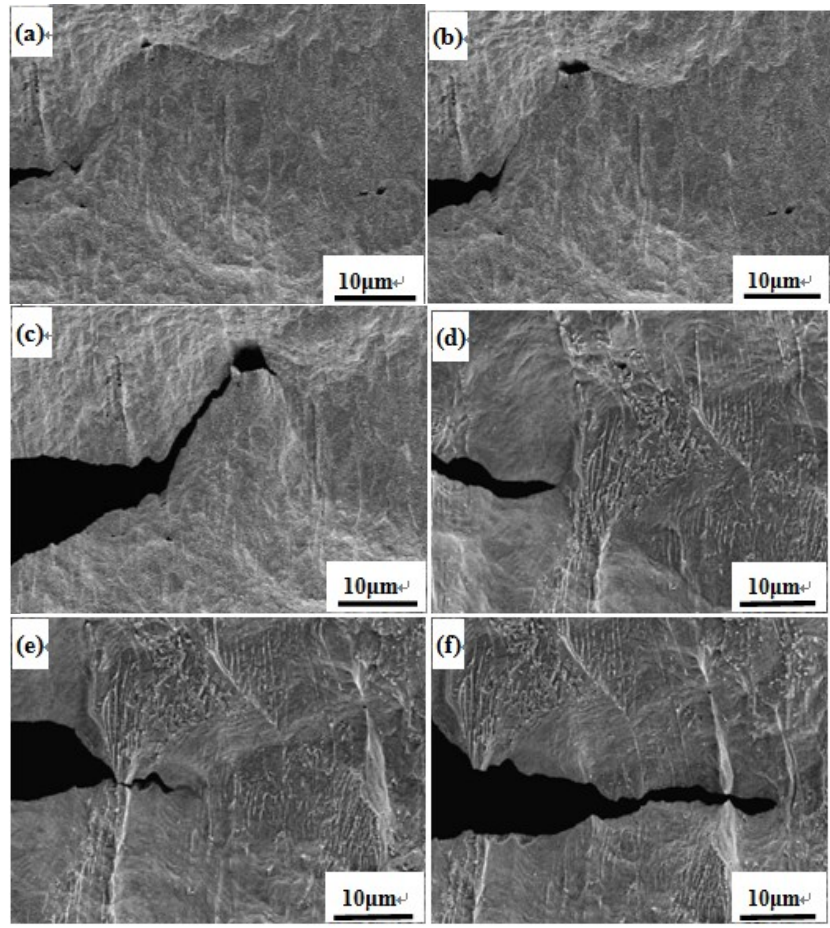

Fig.3. Propagation of crack during tension of QT-treated sample.

The inclusions were always regarded as the crack source, nevertheless, during tension they always ruptured, formed cavity at the junction of inclusion and matrix. As the loading force increased, the cavity extended but not formed crack seen as arrow in Fig.4a. The size of the inclusion was about $3 \mu \mathrm{m}$, affected the plasticity and the toughness. Besides, a small quantity of micro-crack formed within lath martensite and either extended through the lath or connected with main crack. This verified that the nucleation of the crack did not originate from detects of surface, but the concentration of stress.

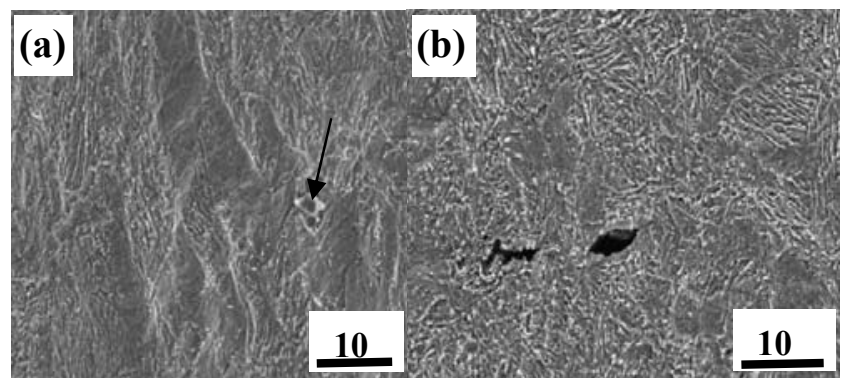

Fig.4. Inclusions in QT-treated sample during tension.

\section{IN-SITU SEM OF FRACTURE IN QLT-TREATED SAMPLE}

Microstructure of sample treated by QLT before tensile test could be seen in Fig.5a. It was showed that high content of retained and reversed austenite in QLT-treated sample was located not only on the high angle grain boundaries such as prior austenite boundary and packet boundary but also within the laths. The evolution of microstructure at tip of the crack was shown in Fig.5b-d. It was indicated that the deformation behavior was similar to QT-treated sample, so were the formation of crack and the propagation. Basically it extended through laths.
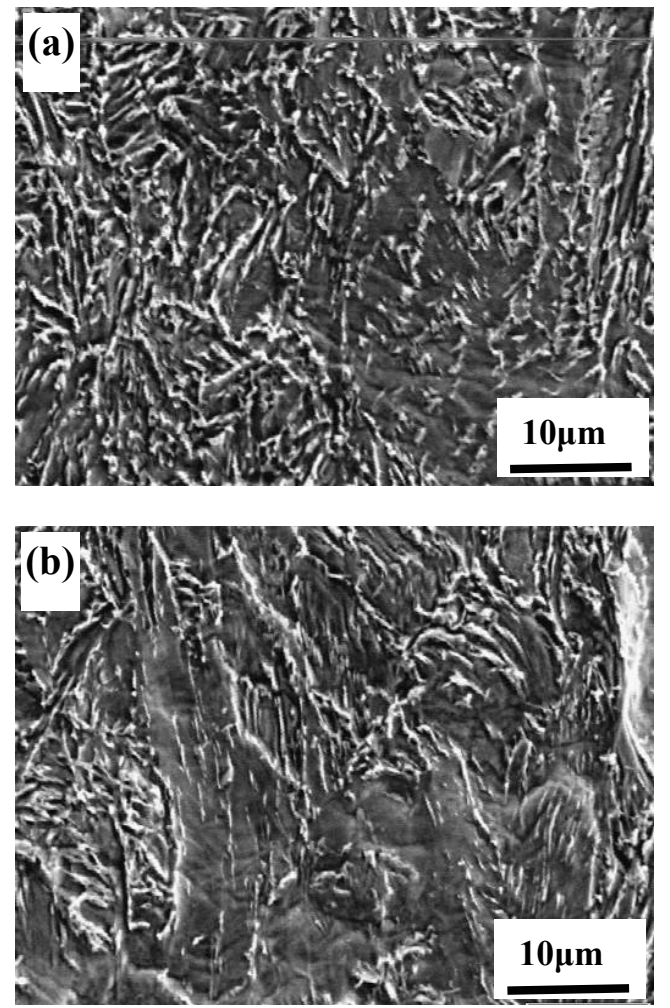

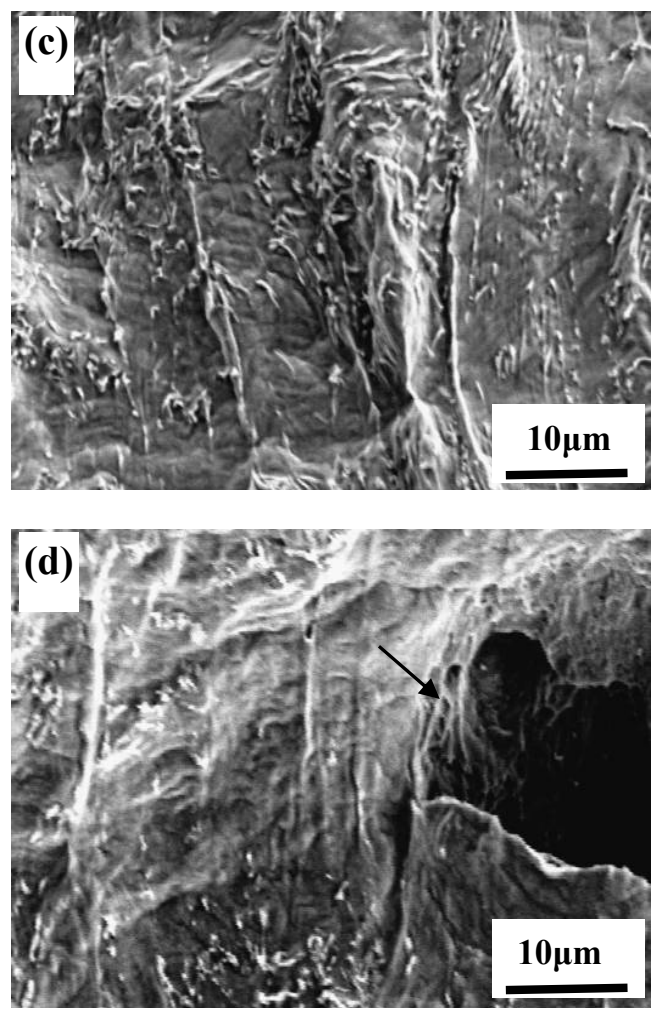

Fig.5. Evolution of microstructure of QLT-treated sample during tension.

The morphology of the crack tip in Fig.3f which was acute angle is different from that in Fig.6d which was obtuse angle. The crack of acute angle intensified the concentration of stress, and it was harmful to the plasticity and the toughness. It was showed in Fig.6d that the matrix could endure much larger plastic deformation, indicating that the retained and reversed austenite improved the plasticity of the matrix significantly, so as to alleviate stress concentration at crack tip and to inhibit extension of crack. Webster ${ }^{[14]}$ thought that retained and reversed austenite can hinder the propagation of the crack which can absorb more energy than the direct propagation. It is reported ${ }^{[15]}$ that austenite transformed into martensite can absorb a large amount of energy in the state of stress-strain, the value is 5 times of shear plastic deformation. We believed that the main toughing reason was the retained and reversed austenite which enhanced the plastic of the matrix and the TRIP effect during deformation process, no matter how stable the retained and reversed austenite was, it could contribute to enhance the cryogenic toughness of $9 \mathrm{Ni}$ steel, the effect of toughing depended on its stability. According to the results, the retained and reversed austenite showed indirect effect on hindering the propagation of the crack, which could enhance plasticity greatly, resist extension of the crack indirectly.

\section{SUMMARY}

The content, stability and distribution of the retained and reversed austenite played vital role in improving cryogenic toughness $\left(-196^{\circ} \mathrm{C}\right)$ of $9 \% \mathrm{Ni}$ steel. The retained and reversed austenite which was stable at low temperature and distributed not only along high angle grain boundaries such as prior austenite grain boundary and packet boundary but also within lath martensite can enhance cryogenic toughness.

The inclusions were always regarded as the crack source, and the crack mainly propagate across lath martensite. The volume fraction of retained and reversed austensite in QLT-treated sample is much higher than that in QT-treated sample, which improve the strength and the toughness.

\section{REFERENCES}

[1] Yeon-Sang Ahn, Hong-Deok Kim, Thak-Sang Byun, et al. Application of intercritical heat treatment to improve toughness of SA508 C1.3 reactor pressure vessel steel. Nuclear Engineering and Design, 1999, 194: 161-177.

[2] Chunling Zhang, Dayong Cai, Bo Liao, et al. A study on the dual-phase treatment of weathering steel 09CuPCrNi. Materials Letters, 2004, 58: 1524-1529.

[3] Nobuo Nakada, Junaidi Syarif, Toshihiro Tsuchiyama, et al. Improvement of strength-ductility balance by copper addition in $9 \% \mathrm{Ni}$ steels. Materials Science and Engineering: A, 2004, 374:137-144.

[4] J. Chiang, B. Lawrence, J. D. Boyd, et al. Effect of microstructure on retained austenite stability and work hardening of TRIP steels. Materials Science and Engineering: A, 2011, 528: 4516-4521.

[5] E.Emadoddin, A.Akborzadeh, Gh.Daneshi. Effect of intercritical annealing on retained austenite characterization in textured TRIP-assisted steel sheet. Materials characterization, 2006, 57: 408-413.

[6] A. Akbarzadeh, G.H. Daneshi. Correlation between Luder strain and retainedaustenite in TRIP-assisted cold rolled steel sheets. Materials Science and Engineering: A, 2007, 447(1-2): 174-179.

[7] Li-jun Wang, Qing-wu Cai, Hui-bin Wu. Effects of tempering temperature on the microstructure and mechanical properties of $1500 \mathrm{MPa}$ grade steel directly quenched. Journal of University of Science and Technology Beijing, 2010, 32(9):1150

[8] Jing C N, Wang Z C, Han F T. Research progress of the influencing factors on transformation induced plasticity. Heat Treatment of Metals, 2005, 30 (2): 26

[9] V.E.Danil chenko, V.V.Sagaradze, Ph. I'Heritier. Martensite crystal structure of nickel steel at cryogenic temperature. Materials Science and Engineering: A, 2003, 358(1-2): 26-31.

[10] utian Zhang, Jingyun Wang, Yunyi Guo. On the relationship between return austenite and toughness for $\mathrm{Ni} 9$ steel at cryogenic temperature. Acta metallurgica sinica (in Chinese), 1984, 20(6): 405-410.

[11] hanwu Yang, Chengjia Shang, Xuemin Wang, et al. Abnormally turning of fine lath-like microstructures in low carbon microalloyed steel during mono-axis tension. Acta metallurgica sinica (in Chinese), 2003, 39 (6): 579-584.

[12] Mishnaevsky L L, Lippmann N, Schmauder S, et al. In-situ observation of damage evolution and fracture in AlSi7Mg0.3 cast alloys[J]. Engineering Fracture Mechanics, 1999, 63(4): 395-411

[13] Yong-hong Wen, Di Tang, Hui-bin Wu, et al. In-situ observation of damage evolution and fracture in B hull structural steel. Journal of Iron and Steel Research, 2009, 21(5): 31-34.

[14] Donald Webster. Development of a high strength stainless steel with improved toughness and ductility [J]. Metallurgical transactions, 1971, 2:2097-2104.

[15] Lai G Y, Wood W E, Clarck R A, et al. The effect of austenitizing temperature on the microstructure and mechanical properties of as-quenched 4340 steel[J]. Metallurgical transactions, 1974, 5: 1663-1670. 